\title{
Artigos
}

\author{
Felipe Luckmann
}

Universidade Federal do Rio Grande do Sul, Porto Alegre, RS, Brasil

Henrique Caetano Nardi

Universidade Federal do Rio Grande do Sul, Porto Alegre, RS, Brasil

\section{Um corpo (des)governado: hierarquias de gênero, governamentalidade e biopolítica}

Resumo: O artigo analisa as articulações entre a governamentalidade neoliberal, a biopolítica e o esquadrinhamento das relações entre sexo, gênero e sexualidade. Busca demonstrar como a desestabilização da lógica identitária binária de gênero ameaça determinadas formas de governar e, também, como a norma pode se reconfigurar produzindo estratégias para incorporar corpos produzidos no avesso do padrão cissexista. Para tanto, o "problema de gênero" causado por Indianara, que se identifica como uma pessoa trans e que foi detida durante uma Marcha das Vadias ao andar com os seios despidos, serviu de analisador dessas articulações, a partir da composição conceitual escolhida.

Palavras-chave: gênero; sexo; sexualidade; biopolítica; governamentalidade

\section{Introdução}

Dia 13 de junho, às $10 \mathrm{~h} 30$, local Rua Humberto de Campos $315 / 2^{\circ}$ andar - Jecrim do Leblon, eu, Indianara Siqueira, serei julgada por Ultraje Público Ao Pudor. Depois das "confusões" criadas na Marcha Das Vadias e criar o protesto "Meu Peito, Minha Bandeira, Meu Direito", onde algumas trans me seguiram, policiais ficaram atentos até conseguirem me deter. Após receber voz de prisão por desacato, ao me negar a assinar o B.O. e liberada após pagamento de fiança feito por companheirxs Vadixs, recebi a intimação do julgamento. Independente do resultado do julgamento e mais que uma pessoa ou um coletivo, o que estará sendo julgado é o gênero, a imagem do feminino que não tem o mesmo direito que o masculino.

\section{(c) (i)}

Esta obra está sob licença Creative Commons. 
A justiça criará também um dilema.

Se me condenar estará reconhecendo legalmente que socialmente eu sou mulher e o que vale é minha identidade de gênero e não o sexo declarado em meus documentos, isso, então, criará jurisprudência para todas xs pessoas trans serem respeitadxs pela sua identidade de gênero e não pelo sexo declarado ao nascer.

Se reconhecer que sou homem, como consta nos documentos, estará me dando o direito de caminhar com os seios desnudos em qualquer lugar público onde homens assim o façam, mas também estará dizendo que homens e mulheres não são iguais em direitos.

To be or not to be.

ICONOCLASTIA INCENDIÁRIA (2013)

O julgamento de Indianara Siqueira nunca ocorreu. O processo foi arquivado após a realização da audiência inicial, já que o policial que autuou Indianara não compareceu perante o Juízo.' Diante da situação paradoxal manifesta no suposto crime cometido por Indianara, que colocou em xeque instituições, leis, estratégias de governo, a resposta do Estado foi o silêncio.

Indianara foi autuada por andar com os seios à vista durante sua participação em uma "Marcha das Vadias", no Rio de Janeiro. Ela foi enquadrada nos artigos 233 e 234 do Código Penal Brasileiro, que tratam do "ultraje público ao pudor" (BRASIL, 1940). Seguiu-se uma discussão com o policial, quando Indianara teria argumentado que, perante a lei, ela seria um homem, já que assim constava em seus documentos, portanto, poderia circular sem blusa. O policial contra-argumentou que, embora ela em seus documentos fosse homem, estava mostrando os seios. Finalmente, foi conduzida a uma delegacia. Ao se recusar a assinar o boletim de ocorrência, Indianara teve a prisão decretada por desacato à autoridade, sendo liberada posteriormente mediante pagamento de fiança.

Estes fatos deram origem a um processo que expunha e, ao mesmo tempo, interrogava uma maneira de governar baseada na divisão binária e identitária dos sexos. O corpo de Indianara, ao desafiar as normas regulatórias da sociedade, assume também "o desconforto da ambiguidade, do 'entre lugares', do indizível" (Guacira Lopes LOURO, 2004, p. 8) e materializa uma subversão da matriz de inteligibilidade do gênero, constituída pela ordem compulsória sexo-gênero-desejo (Judith BUTLER, 2003). O que está em jogo, portanto, é um tensionamento cuja potencialidade vai muito além do delito de ultraje ao pudor.

Qual foi, afinal, o crime de Indianara? Que "delito" mais geral estaria sendo julgado? Colocando a questão dentro uma perspectiva mais ampla, qual o "problema" que as/os transgêneros criam? A resposta final à celeuma criada por Indianara foi reticente. Qual o significado do silêncio da polícia e o consequente não prosseguimento do litígio? Não seria isso a repetição de uma política que cala e nega a existência desses corpos potencialmente subversivos?

Este mutismo denuncia o fato de que só os corpos normalizados conforme as exigências do imperativo cisgênero têm o direito de existir, enquanto os demais são relegados à esfera da abjeção. Seus corpos estão expostos a violências de ordem física, política e social. A abjeção, por exclusão, circunscreve o campo de existência dos sujeitos (Maria Juracy Filgueiras TONELI e Marília dos Santos AMARAL, 2013). Este movimento excludente pode ser percebido no âmbito das políticas públicas no Brasil, tendo em vista que, conforme levantamento realizado por Maria Juracy Toneli e Marília dos Santos Amaral, as políticas

\footnotetext{
' A filmagem do desenrolar da manhã em que foi realizada a audiência está disponível em http:// www.youtube.com/watch?v=Bew-QGZJXDg.
} 
estão atreladas, no caso dos/das transgêneros, às drogas e à prevenção das DSTs e da criminalidade, havendo, portanto, um "abandono analítico de outras esferas sociais tais como educação, moradia e segurança pública" (TONELI e AMARAL, 2013, p. 37).

A situação de vulnerabilidade à violência destes corpos considerados abjetos tampouco pode ser desconsiderada. Conforme dados da organização não governamental Transgender Europe (TGEU), o Brasil está no topo da lista em número de assassinatos de transexuais e travestis, dentre 57 países, com o assombroso número de 452 mortes entre 2008 e 2012 (TONELI e AMARAL, 2013).

É preciso, portanto, fazer coro aos movimentos sociais que colocam o problema trans no âmbito mais amplo da cidadania e dos direitos humanos. É preciso indagar a forma como a noção de gênero, nas sociedades ocidentais, tem servido de apoio fundamental a práticas biopolíticas, efetuando uma interrogação crítica de formas específicas de governar. Em consonância com o pensamento de Michel FOUCAULT (1990), que relaciona a crítica à reflexão sobre as formas de governar, o problema seria menos negar a governamentalidade em si do que se pensar se é dessa maneira e a esse preço que se quer ser governado. Esta é, em linhas gerais, a temática que orienta este ensaio.

Por qual razão o acontecimento narrado por Indianara é ponto de partida deste artigo? Sobretudo porque o paradoxo estabelecido nos acontecimentos narrados por Indianara é um analisador das interrogações que o configuram. Toma-se o conceito de analisador do campo da análise institucional, entendido como um acontecimento, ao mesmo tempo revelador e catalisador, que traz à tona a instituição invisível, conferindo maior força à análise (René LOURAU, 1993, 2004).

Primeiramente e, grosso modo, estas são as indagações aqui propostas: as descontinuidades de gênero que subvertem a lógica identitária podem também desestabilizar determinadas formas de governar? Quais tipos de estratégias de governo se apoiam ou, mesmo, produzem a matriz de inteligibilidade de gênero dominante? Considerando que saber e poder são indissociáveis (FOUCAULT, 1999), de que maneira um corpo que não está modelado na norma cissexista de gênero pode ser capturado por novas estratégias governamentais?

Tal pretensão de problematização implicará discorrer sobre o surgimento da arte de governar e, como corolário, de uma política da vida; discorrer sobre a construção de estratégias articuladas à biopolítica, lhe conferindo eficácia, dentre as quais são mais notáveis, mas não as únicas, a sexualidade e o gênero; e, por fim, exigirá pensar como os estudos de gênero se articulam com essas perspectivas.

\section{A arte de governar e a biopolítica}

A ideia de um "governo dos homens", de acordo com Michel Foucault (1990), remonta à lógica da pastoral cristã, a qual propunha que os indivíduos, em toda a extensão de suas vidas e de suas ações, deveriam ser governados e se deixarem governar por alguém que os conduzisse à salvação, numa relação global de estrita obediência. Tal arte de governar permaneceu relativamente limitada até a Reforma Protestante, quando houve sua difusão ao campo mais amplo do governo das populações. Essa expansão corresponde, primeiramente, ao seu deslocamento do foco religioso para a sociedade civil - é a laicização da arte de governar. Um segundo ponto é a multiplicação das áreas de atuação deste governar: como governar as crianças, os pobres, a família, uma casa, uma cidade, o Estado e, também, no âmbito individual, o corpo e o espírito.

Governamentalidade diz respeito, portanto, a uma gama de modos de problematização e ação sobre as condutas individuais e coletivas, cujos fins e objetivos 
incluem, mas também extrapolam o âmbito do Estado (Paul RABINOW e Nikolas ROSE, 2006).

Uma das consequências da difusão dessa arte de governar foi o surgimento de uma atitude crítica que tinha como interrogação justamente o outro lado da moeda: como não ser governado? Qual a justa medida do governar? (FOUCAULT, 1990).

Em um dos seminários de Foucault no Collège de France, publicado posteriormente sob o título de Nascimento da Biopolítica, Foucault (2008) discorre longamente sobre a emergência da governamentalidade desde o século XVIII e as tensões entre o papel do Estado, especialmente a justa medida de seu governo e as teorias econômicas, particulamente as liberais. A liberdade passa a ser essencial para o modo liberal de governar que se afirma no século XIX, pois é na liberdade dos indivíduos que a governamentalidade se assenta. Em um campo em que se criam as liberdades individuais, os diferentes interesses, muitas vezes divergentes, devem ser governados de modo a garantir a própria liberdade e segurança de todos. Esta é a economia característica do poder liberal: gestão de seguranças e de liberdades.

Porém, de um modo paradoxal, poderia se afirmar que o lema do liberalismo é "viver perigosamente" (FOUCAULT, 2008, p. 90). Esse mote traduz o sentimento que os indivíduos têm de estarem constante e perpetuamente expostos ao perigo e, mais fundamentalmente, condicionados a vivenciarem seu presente e futuro como perigosos, com ênfase nos riscos ordinários, cotidianos. Como exemplo, Foucault $(2008, p .91)$ traz a sexualidade e o medo da degeneração - "degeneração do indivíduo, da família, da raça, da espécie humana".

Foucault (2008, p. 90-91) conclui que "não há liberalismo sem cultura do perigo e, de forma paradoxal, uma consequência dessa arte liberal de governar é "a formidável extensão dos procedimentos de controle, de pressão, de coerção que vão construir como que a contrapartida e o contrapeso das liberdades. Diferentemente do panoptismo, a liberdade é o próprio motor gerador do controle. A cada "a mais" de liberdade concedida corresponde um "a mais" de controle. É neste âmbito que irão se inserir todos os problemas e contradições em torno das políticas consideradas sociais - um controle a mais, uma intervenção a mais na economia, para garantir as liberdades individuais e, é claro, a continuidade do funcionamento do mercado econômico (FOUCAULT, 2008).

O processo acima delineado parece se aprofundar com o advento do neoliberalismo. A respeito do contexto alemão do neoliberalismo, Foucault (2008) afirma que

tanto a intervenção governamental deve ser discreta no nível dos processos econômicos propriamente ditos, como, ao contrário, deve ser maciça quando se trata desse conjunto de dados técnicos, científicos, jurídicos, demográficos, digamos, grosso modo, sociais, que vão se tornar cada vez mais o objeto da intervenção governamental (p. 194).

Essas intervenções sociais mencionadas por Foucault (2008) têm por objetivo manter a ordem concorrencial do mercado, ou seja, propiciar que a própria liberdade entre os agentes econômicos do mercado seja exercida. A livre concorrência seria propriamente o princípio regulador da sociedade. A sociedade, de acordo com o funcionamento neoliberal, seria constituída por "empresas individuais", ou seja, há a transposição do padrão de funcionamento da empresa ao nível do indivíduo, da sua vida. Vemos aí o gérmen do que será, mais tarde, a definição norte-americana de capital humano, do autoempreendedor e, cabalmente, a emergência de um homo oeconomicus, empresário de si mesmo.

Uma consequência importante dessa transposição do funcionamento da empresa ao nível do indivíduo é a emergência da noção de capital humano. Essa noção diz 
respeito à indissociabilidade do rendimento ou salário que determinado sujeito recebe em relação à competência-máquina de que ele é portador. Passa-se, então, no contexto do neoliberalismo, a se pensar em como tornar mais atrativo e rentável esse capital humano. Entendemos, portanto, que se abre um campo privilegiado de intervenção governamental sobre a vida, prescrevendo uma série de estratégias e exercendo um sem número de controles para fazer prosperar esse capital humano (FOUCAULT, 2008).

Entende-se, assim, a vida como um campo privilegiado de atuação governamental a partir do liberalismo, intensificando-se no neoliberalismo. Certamente, não é uma questão de governo no sentido puramente estatal. O próprio Foucault (2008) reconhece que a atuação estatal estaria se transformando, a despeito de uma crescente fobia estatal e da percepção de uma interferência excessiva do Estado na sociedade ou na economia. Conforme o autor já havia declarado a respeito da sexualidade e, certamente por decorrência lógica, o poder sobre a vida emana de lugares diversos, apoiando-se em diferentes estratégias (FOUCAULT, 2006). No resumo do curso Nascimento da Biopolítica Foucault (2008) propõe uma definição de biopolítica que converge para as conclusões apresentadas no primeiro volume da História da Sexualidade:

Entendia por isso [a biopolítica] a maneira como se procurou, desde o século XVIII, racionalizar os problemas postos à prática governamental pelos fenômenos próprios de um conjunto de viventes constituídos em população: saúde, higiene, natalidade, longevidade, raças... Sabe-se o lugar crescente que esses problemas ocuparam desde o século XIX e que desafios políticos e econômicos eles vêm constituindo até hoje ( $p$. 431).

Saúde, higiene, natalidade, longevidade, raças. O dispositivo privilegiado, conforme veremos a seguir, que a razão governamental enquanto política da vida irá se apoiar para dar conta destes fenômenos, é a sexualidade.

\section{A sexualidade e a verdade do sujeito}

No primeiro volume da História da Sexualidade, Foucault (2006) afirma que, desde o século XVI, com intensificação a partir do século XIX, houve uma incitação, como não vista antes, para se falar sobre o sexo. Incitação, portanto, contemporânea à emergência da arte liberal de governar e que propiciou a constituição de um campo de saber científico relativo ao sexo e suas mazelas.

Nesse sentido, Foucault (2006) diz que, na cultura ocidental moderna, emergiu uma scientia sexualis, na qual cabe ao indivíduo, cuja prática sexual está sob análise, confessar e falar sobre seu sexo incessantemente; o poder, porém, não está em sua posse, tampouco o saber - em outras palavras, o discurso de verdade sobre seu sexo. Compete ao cientista (psiquiatra, médico, psicólogo, pedagogo etc.), a partir da confissão empreendida pelo indivíduo, extrair sua verdade última, verdade sobre o sexo que escapa ao confidente. Nesse processo de falar incessantemente sobre o seu sexo, outorgando a outro a atribuição de verdade, é que "a confissão da verdade se inscreveu no cerne dos procedimentos de individualização pelo poder" (FOUCAULT, 2006, p. 67).

De acordo com Foucault (2006), a sexualidade é um dos elementos dotados de maior instrumentalidade nas relações de poder, "utilizável no maior número de manobras, e podendo servir de ponto de apoio, de articulação às mais variadas estratégias" (p. 114). Daí configurar-se como campo privilegiado de atuação governamental. O autor aponta para quatro conjuntos de estratégias que engendram poder, saber e sexo a partir do século XVIII: a histerização do corpo da mulher; a pedagogização do sexo da criança; a socialização das condutas de procriação; e, por fim, a psiquiatrização do prazer perverso. 
Ao falar da psiquiatrização do prazer perverso, a título ilustrativo, é interessante retomar um dos aspectos da arte liberal de governar: a gestão de seguranças e liberdades, e o correlativo perigo iminente da vida e do viver (FOUCAULT, 2008). O autor comenta a respeito de um escrutínio e atuação crescentes tanto no âmbito do judiciário como no âmbito da medicina para diagnosticar uma perversão, ou para enquadrar os mais pequenos delitos sexuais, com a suposta prerrogativa de promover a segurança dos corpos saudáveis:

Todos esses controles sociais que se desenvolveram no final do século passado e filtram a sexualidade dos casais, dos pais e dos filhos, dos adolescentes perigosos e em perigo - tratando de proteger, separar e prevenir, assinalando perigos em toda a parte, despertando as atenções, solicitando diagnósticos, acumulando relatórios, organizando terapêuticas; em torno do sexo eles irradiam os discursos, intensificando a consciência de um perigo incessante que constitui, por sua vez, incitação a se falar dele (FOUCAULT, 2006, p. 37).

O corpo torna-se, portanto, palco das mais variadas estratégias e artimanhas do poder e do saber. Isto se dá através da consolidação do dispositivo de sexualidade, que surge em complementação e articulado com o dispositivo de aliança. O último tem caráter de hereditariedade e filia-se à ideologia do clã - as alianças são concebidas em termos de crescimento econômico para as linhagens, manutenção e expansão de riquezas. Há o privilégio do matrimônio, da família e da reprodução (FOUCAULT, 2006).

O dispositivo de sexualidade, por sua vez, não dá ênfase às ligações duradouras, porém aos prazeres e sensações corporais, por mais sutis que sejam. O corpo torna-se o principal alvo deste dispositivo e é através dele que se engendram "articulações numerosas e sutis" com a economia - é o "corpo que produz e consome" (FOUCAULT, 2006, p. 118). O corpo a ser investido, no sentido econômico: o capital humano.

A articulação entre os dispositivos de sexualidade e de aliança mostra-se especialmente eficaz para a domesticação e normalização dos sujeitos, e a sexualidade passa a configurar o núcleo identitário do sujeito. A verdade do sujeito é a verdade sobre o seu sexo (FOUCAULT, 2006). Pode-se pensar que esta vontade de saber descrita até aqui em relação à sexualidade, que faz com que se fale incessantemente sobre o sexo, é correlata a uma vontade de governar. Novamente, saber e poder estão sempre associados.

Nas obras aqui mencionadas, embora Foucault tenha tratado das relações estabelecidas entre poder, sexualidade e constituição da verdade sobre o sujeito, sua problematização não questiona diretamente a produção de gênero como produtora de inteligibilidade dos corpos, deixando de interrogar o binarismo masculino-feminino. Mais precisamente, a ênfase da análise não recai sobre a noção de gênero, ${ }^{2}$ eclipsando um aspecto importante no entendimento da constituição de uma noção específica de identidade - a de uma identidade sexual-generificada. Portanto, é importante prosseguirmos nossa análise através da problematização do conceito de gênero e, mais além, do sistema sexo-gênero.

\section{A invenção do gênero}

O conceito de gênero emergiu no âmbito dos estudos feministas com a finalidade de diferenciar os aspectos anatômico-biológicos daqueles culturalmente construídos que

\footnotetext{
${ }^{2} \mathrm{O}$ conceito de gênero não estava presente no debate acadêmico francês. O movimento feminista francês, com forte influência marxista, na época de lançamento da História da Sexualidade, utilizava o conceito de relações sociais de sexo.
} 
conformariam as diferenças entre homens e mulheres. Portanto, "gênero" funcionava como contraponto ao termo "sexo", pois este carregaria uma faceta determinista que as teóricas feministas repudiavam (Joan SCOT, 1990). O gênero, nesse contexto, dizia respeito a papéis sociais esperados dos homens e das mulheres, deslocando a noção de "ser homem" e "ser mulher" para o âmbito de uma construção cultural, caracterizando-se, assim, como uma "categoria social imposta sobre um corpo sexuado" (SCOT, 1990, p. 7).

Em outro artigo clássico dos estudos feministas, "Gênero: uma categoria útil de análise histórica", a historiadora americana Joan Scott (1990) discute as limitações e impasses encontrados por diferentes pensadoras feministas utilizando-se do conceito de gênero, que falharam em não considerá-lo enquanto categoria de análise e, o mais importante, no seu caráter de constructo histórico. Às vezes ele aparece subordinado às relações econômicas e de produção; em outros momentos, limitado à identidade e à constituição psíquica. Parece limitado, pois, a uma oposição binária (masculino/feminino) com ares de fixidez e a-historicidade. A autora propõe, então, que o gênero seja considerado como uma categoria de análise histórica, o que significaria

analisar dentro do seu contexto a maneira pela qual opera toda oposição binária, derrubando e deslocando sua construção hierárquica, em lugar de aceitá-la como real, como evidente por si ou como sendo da natureza das coisas (SCOT, 1990, p. 13).

Joan Scott (1990) se aproxima do pensamento de Michel Foucault apoiando-se em sua concepção de poder para pensar o gênero para além do patriarcalismo, das relações de parentesco, do materialismo histórico ou dos jogos identitários psicanalíticos. De modo bastante enfático, a autora aponta que "o gênero é um elemento constitutivo de relações sociais fundadas sobre diferenças percebidas entre os sexos, e o gênero é um primeiro modo de dar significação às relações de poder" (SCOTT, 1990, p. 14).

Embora Foucault, conforme já mencionado, não tenha recorrido explicitamente ao conceito de gênero ao tratar da genealogia do dispositivo de sexualidade, fica evidente que este dispositivo se apoiou de diferentes maneiras nas diferenciações simbólicas e concretas entre homens e mulheres para lhe conferir maior eficácia, em um movimento ao mesmo tempo produtivo e reiterativo.

\section{Desconstruindo a oposição sexo-gênero e o problema da verdade do sujeito}

No Prefácio de sua obra Problemas de Gênero, Judith BUTLER (2003) menciona a importância que a historiadora Joan Scott teve como interlocutora na construção do livro. Tal influência mostra-se no decorrer de sua exposição, na medida em que a autora radicaliza, desestabiliza e, por fim, desconstrói a distinção entre natureza/corpo e cultura/gênero. De que maneira ocorre tal desestabilização?

Primeiramente, o raciocínio empreendido é de que, se o gênero é a inscrição da cultura no corpo biológico, tratando-se, portanto, de duas dimensões distintas (natureza e cultura), não haveria, a priori, uma ordem necessária entre estas duas esferas. Ou seja, nada impediria, por exemplo, que em um corpo anatomicamente feminino se inscrevesse um gênero masculino, já que estas seriam esferas distintas e independentes (BUTLER, 2003). Entretanto, Butler (2003) considera que, paradoxalmente, o conceito de gênero, na prática, não acarreta tal maleabilidade. A concepção de gênero, em oposição a um sexo biológico, embora por dedução lógica abra espaços de rupturas e descontinuidades entre estas duas categorias, por outro lado traz implícito em seu entendimento "a crença numa relação mimética entre gênero e sexo, na qual o gênero reflete o sexo ou é por ele restrito" (BUTLER, 
2003, p. 24). A maneira binária como o gênero tem sido compreendido é o motivo de tal relação mimética.

Diante dessa constatação, Butler (2003) inverte a formulação usual, propondo que a construção da categoria "gênero" emerge como discurso produtor de sexos inteligíveis dentro do binarismo masculino/feminino. Portanto, é preciso compreender não apenas o caráter de construção histórico-social do gênero, mas também do próprio sexo, de forma que a distinção entre gênero e sexo torna-se nula. Butler (2003) ressalta, portanto, a impossibilidade de se pensar o corpo como um fato pré-cultural, a-histórico, imaculado pelo discurso. Conclui, então, que o sexo "será sempre apresentado, por definição, como tendo sido gênero desde o começo" (BUTLER, 2003, p. 27).

Não se trata da negação da materialidade dos corpos, mas sim da afirmação das práticas discursivas que os constituem como corpos "masculinizados" ou "feminilizados". Inexiste um corpo fora da cultura/discurso, um suposto corpo "pré-cultural" (LOURO, 2004).

A título ilustrativo, cabe aqui uma pequena digressão histórica em relação aos discursos que em diferentes épocas conformaram determinadas visões dos corpos. A emergência do dimorfismo dos corpos é contemporânea à emergência da biopolíica. Berenice BENTO (2006), ao retomar a análise de Thomas Laqueur, afirma que, para a ciência anterior ao século XVIII, os corpos diferenciavam-se não por duas formas anatômicas diametralmente distintas (masculino e feminino), mas sim por um espectro de intensidades. O corpo masculino era aquele entendido como o desenvolvido plenamente, em decorrência de ter recebido "mais calor" (ou energia vital). Este calor seria o responsável pela exteriorização da genitália. O corpo feminino, por outro lado, teria recebido "menos calor", permanecendo a genitália interna ao corpo. A vagina seria um pênis invertido. Entendiase, assim, que os corpos eram originalmente iguais, tendo como diferenciadores estas intensidades diversas de calor. Como consequência, aceitava-se que uma pessoa se transformasse de mulher para homem, por exemplo, em decorrência de um evento extremo, que faria com que as genitálias se externassem. O dimorfismo sexual, a partir do século XVIII, substituiu o isomorfismo, respondendo uma necessidade política de diferenciar homens e mulheres num nível biológico, onde não apenas as genitálias, mas os ossos, os nervos, os músculos, diferenciavam-se (BENTO, 2006).

Na metade do século XIX, os corpos científicos "masculinos" e "femininos" estavam constituídos e os órgãos, batizados: vagina, útero, trompas, mamas etc. Ocorre, então, a inversão dos termos sexo-gênero: "os corpos-sexuados que foram inventados pelos interesses de gênero ganharam o estatuto de fato originário" (BENTO, 2006, p. 116).

Butler (2003, p. 28) afirma que existem limites discursivos que antecipam e restringem as formas realizáveis e mesmo imagináveis do gênero na cultura, cujas estruturas são binárias e adquirem ares de uma racionalidade universal. É no bojo do "domínio imaginável do gênero" que a coerção é introduzida, através da linguagem.

Neste sentido, quando um feto é nomeado como um "menino" ou uma "menina", ocorre um apagamento de sua produção histórica, numa lógica a-cultural, a-histórica, imutável e binária, ou seja, determinado sexo (macho/fêmea) desencadeará determinado gênero (masculino/feminino) e, consequentemente, induzirá a uma forma de desejo compulsória (pelo sexo oposto, ou seja, heterossexual) (LOURO, 2004).

Problematizando o conceito de identidade que, na filosofia ocidental, tende a ser vista como única e idêntica a si mesma, Butler (2003, p. 39) aponta que esta concepção é sustentada justamente pelo discurso de inteligibilidade do gênero baseado em estruturas binárias. A matriz cultural de inteligibilidade supõe o ordenamento antes mencionado determinado sexo determinará um gênero específico e, por consequência, um desejo

1246 Estudos Feministas, Florianópolis, 25(3): 1239-1255, setembro-dezembro/2017 
decorrente - e, para que esta matriz seja sustentada, reitera que determinados tipos de identidade, que não sigam esta linha de continuidade (sexo - gênero - desejo), não devem existir. Estas identidades, por escaparem às regras de entendimento cultural, são entendidas como "erros" de desenvolvimento ou ilógicas. Porém, tais "equívocos" ou desvios emergem incessantemente e são oportunidades de crítica ao sistema hegemônico de inteligibilidade, disseminando, dentro dessa matriz, sistemas "rivais e subversivos de desordem de gênero".

Quando os sujeitos não correspondem ao sistema hegemônico de inteligibilidade, eles expõem o caráter performativo do gênero. A ideia de performatividade busca subverter a lógica da expressão, na qual os atos do sujeito (gestos, falas etc.) seriam expressões de uma identidade de gênero pré-concebida, reforçando a ideia de sexos/gêneros naturais. Em contrapartida, entendendo os atos do sujeito como performativos, frisa-se que esses atos não são expressão de um gênero substantivo, mas o constituem (BUTLER, 2003).

Butler (2003) ressalta que mediante atos, gestos e desejos postos em ação, há a criação de uma ilusão de "um núcleo interno e organizador do gênero" (p. 195). Esta ilusão é sustentada discursivamente com o objetivo de regular a sexualidade dentro dos parâmetros da matriz heterossexual de inteligibilidade. Tal coerência, dentro dos parâmetros da matriz heterossexual, acaba sendo desejada pelos sujeitos, por meio de mecanismos coercitivos de sujeição à norma. Como consequência, são produzidos "corpos que expressam essa lei no corpo e por meio dele; a lei se manifesta como essência do eu deles, significado de suas almas, sua consciência, a lei de seu desejo" (BUTLER, 2003, p. 193). Portanto, ficam obscurecidos os aspectos de interioridade e exterioridade. A norma produz e, mesmo que a identidade de gênero seja performativamente constituída, ou seja, produzida discursivamente, ela mantém uma aparência de interioridade.

Entendendo o gênero como performativo e não como essência, de que forma ele se constitui? Constitui-se no tempo e no espaço público, mediante uma repetição estilizada de atos. É uma forma corriqueira, num nível coletivo e público, em que "gestos, movimentos e estilos corporais de vários tipos constituem a ilusão de um eu permanente marcado pelo gênero" (BUTLER, 2003, p. 200). Estes atos repetidos buscam corroborar o ideal de uma identidade de gênero subjacente a estes atos. Porém, por tal identidade ser, na verdade, efeito destes atos, há um espaço para que haja descontinuidades nestes atos repetidos. Falhas, "anomalias" podem ocorrer (BUTLER, 2003).

Se não há um ser por trás do agir e a ação é tudo, entendemos que não há um gênero original, mas sempre cópias, paródias, aproximações incessantes (BUTLER, 2003). Não há um rosto por trás das máscaras - o que há são somente máscaras em constante sucessão. Subvertendo uma visão essencialista e entendendo a identidade enquanto devir, os autores Ricardo Pimentel MÉLLO e Ângela Flexa PAOLO (2007), apoiando-se no pensamento de Gilles DELEUZE (2008), apontam que somos uma sucessão de máscaras:

Nenhum matiz identificatório é fixo, sólido e estável, mas fluido, intercambiante, em vias de se fazer, possibilitando às pessoas transitar por formas diversas, construir modos de ser, assumir posições, descartá-las e utilizá-las de novo. Seria como nos carnavais, em que inúmeras máscaras se metamorfozeiam em corpos, se encontram num espetáculo de cores e formas, sem querer restituir a essência de quem as usa (revelando um rosto por trás das máscaras), mas abrindo possibilidades de mudanças, de performances, de flutuações, num movimento que põe em jogo mais os desejos de devir do que possíveis essencializações e classificações, dando continuidade ao processo de constituir-se, subjetivar-se, dobrar-se, constituindo corpos que só têm máscaras, e estas, definitivamente, não são falsidades ou escudos de um rosto essencial (MÉLLO e PAOLO, 2007). 
Chegamos, aqui, ao falar de denúncias, desordens, performatividades, máscaras e carnavais ao ato subversivo de Indianara que iniciou este ensaio. É a partir do problema de gênero exposto por ela que se empreenderá a discussão do próximo bloco, no qual, mediante a articulação dos conceitos apresentados até aqui, será proposto compreender o que o gênero e suas desordens denunciam a respeito das artes de governar.

\section{O sexo (des)governado}

No Código Civil Brasileiro (BRASIL, 2002), no capítulo que trata dos Direitos de Personalidade e na lei geral que regulamenta os registros públicos (BRASIL, 1973), está firmado o direito básico de toda/o brasileira/o receber um nome e o dever de cada criança nascida ser devidamente registrada, constando no registro o nome, a data e horário de nascimento e, também, o sexo. O indivíduo nomeado e registrado carregará essas referências que lhe foram dadas até a morte. O peso a ser carregado, porém, é variável e depende de uma das primeiras intervenções biopolíticas que o corpo receberá. O cisgênero, cuja "primeira cirurgia" 3 foi mais bem-sucedida do que a da/o transgênero, pois goza da legitimidade social que a norma concede, vai vivenciar o seu nome de maneira distinta.

Apresentar o documento de identidade, onde estão inscritos o número de Registro Geral, data de nascimento, naturalidade, nome dos pais, foto, prenome e sobrenome, a fim de identificar-se, é ato banal para uma pessoa cisgênera. O sexo não é mencionado no documento, mas o nome dado ao nascimento, devidamente generificado, suprime essa necessidade.

A menção do documento de identidade no início desta seção não é gratuita, já que não é simplesmente um documento descritivo e localizador do sujeito em determinado ponto do campo social. Conforme Henrique Caetano NARDI (2014), o documento tem seu peso próprio, ou seja, é performativo: "diga-me quem és e te direi quais direitos possui". Essa característica performativa é importante, considerando que a noção de sujeito "da identidade" é correlata e pressuposta do sujeito livre neoliberal - o homo oeconomicus - e portanto, alimenta o motor da arte liberal de governar, composto por liberdades (FOUCAULT, 2008). Nardi (2014) alerta para os riscos dessa artimanha:

O jogo é arriscado, pois o Estado, pelo menos na sua forma moderna e contemporânea, se alimenta de identidades. Ou seja, ele define no jogo político, quem merece direitos e proteção e, ao fazê-lo, põe em ação a máquina burocrática de identificação dos cidadãos e das cidadãs (p. 222).

Primeiro ponto a destacar aqui é a relação que se estabelece entre a burocracia que identifica cidadãos e a garantia de direitos e proteção. Nesse sentido, pode-se retomar a assertiva de Foucault (2008) que considera que a economia característica do poder liberal é a gestão de seguranças e de liberdades, constituído em decorrência "[à] a formidável extensão dos procedimentos de controle, de pressão, de coerção que vão construir como que a contrapartida e o contrapeso das liberdades" (p. 91). Tal gestão apoia-se na concepção identitária que, por sua vez, retomando o pensamento de Butler (2003), está intimamente relacionada à noção de gênero enquanto substantivo.

O segundo ponto a destacar é o acesso diferenciado a direitos e proteção, conforme o resultado do processo burocrático identificatório. Nessa esteira e, ao se pontuar a

\footnotetext{
${ }^{3} \mathrm{~A}$ ideia de que todas/os somos operadas/os e que, portanto, os corpos já nascem operados e são investidos durante toda a vida por tecnologias sociais precisas, é de autoria de Beatriz Preciado (2002, apud BENTO, 2006). No caso do/da transexual, a cirurgia inicial não teria sido bem-sucedida no sentido de que o "corposexuado que lhe foi atribuído não serve para lhe conferir sentido" (BENTO, 2006, p. 89).
} 
importância da verdade do sujeito que reside em sua sexualidade generificada, pode-se retomar a definição de Scott (1990), que aponta como o gênero é uma forma primordial de se dar significação às diferenças atribuídas aos sexos. Estas diferenças são sustentadas por regimes de verdade a respeito dos corpos, compreendidos a partir do binarismo isomorfismo/dimorfismo (BENTO, 2006), conferindo um acesso diferencial a fontes materiais e simbólicas (SCOTT, 1990). Mas, e se a diferença entre os sexos é deliberadamente embaralhada, como o fez Indianara?

Pode-se inferir que Indianara expõe uma fragilidade nesse sistema identificatório e o desconcerta. Seu corpo desestabiliza a matriz cultural de inteligibilidade de gênero, que funciona binariamente e mediante a heterossexualidade e o cissexismo compulsórios, borrando a suposta fronteira entre cultura e natureza. Ao embaralhar a regra de entendimento cultural, produz a crítica a esse sistema. Ao mesmo tempo em que possui um documento cujo prenome é generificado masculinamente, mas anda com os seios despidos, considerados anatomicamente com um traço feminino, Indianara performatiza um gênero desordenado, em uma acepção positiva de desordem. Conforme Butler (2003), este desvio, ao ocorrer dentro da própria matriz cultural de inteligibilidade, cria sistemas "rivais e subversivos de desordem de gênero" (BUTLER, 2003, p. 39).

Todavia, tais desgovernos nem sempre passam impunes: Indianara foi enquadrada criminalmente e seguiram-se os constrangimentos narrados na introdução. Estas identidades desconcertantes, se não forem objeto de coerção policialesca ou médico-psiquiátrica, podem alternativamente sofrer cerceamentos e constrangimentos cotidianos de magnitudes variadas. Nesse sentido, Camila GUARANHA e Eduardo LOMANDO (2013) descrevem as vicissitudes enfrentadas por transgêneros ao acessarem os serviços públicos, em decorrência de, às vezes, deliberadamente, não ser respeitado o uso do nome social, embora em muitos estados e em diferentes esferas administrativas já exista legislação obrigando o seu uso. As/ os atendentes dos serviços contrariam a lei em nome da norma, do bom governar, fazendo valer as estratégias de controle alicerçadas no dispositivo de sexualidade e na generificação dos corpos. No mesmo espírito, Bento (2006) descreve o processo de "assepsia de gênero" que incide sobre as candidatas à cirurgia de transgenitalização em um hospital de Goiânia, levado a cabo pelos profissionais de saúde que compõem a equipe responsável. Diante desses exemplos, cabe retomar aqui o pensamento de Foucault (2006) a respeito do poder, que o entende como imanente a todas as relações sociais, não sendo exercido simplesmente de cima para baixo, ou do aparelho de Estado sobre os indivíduos. A governamentalidade produz, portanto, todo o tecido social. Assim, é uma condução de condutas que não se operacionaliza somente mediante ações estatais, mas conta com apoios diversos e difusos.

Cabe aqui uma digressão a respeito do conceito de "nome social". Embora seja um avanço, no sentido de abertura à garantia de direitos, devemos questionar as implicações deste conceito, pois parece que o corolário desse termo é um nome mais verdadeiro, em oposição ao nome social - um nome não social, ou seja, natural. Cai-se facilmente na armadilha que as dicotomias natureza-cultura e sexo-gênero representam. Ademais, esta situação serve de analisador para o regime de verdade que estabelece que a verdade do sujeito está em sua sexualidade, em seu gênero (GUARANHA e LOMANDO, 2013).

Entretanto, ao entendermos gênero como performativo, aproximação incessante e nunca completa a um gênero mítico, mas suposto como autêntico que, por isso mesmo, é ficcional, poderia se pensar em um nome mais verdadeiro? A concepção de um nome factual é correlata à ideia de uma identidade fixa (no sentido psicológico e documental). O nome, como uma máscara, também pode ser intercambiável - e não há um rosto por trás das máscaras. O nome de registro civil, o nome de batismo dado por uma travesti mais 
velha, o apelido, o nome artístico da drag queen ou do drag king, a simples inflexão do nome atribuído ao nascimento para o gênero de identificação, enfim, todas essas possibilidades se sucedem, se alternam (Marcos BENEDETTI, 2005). Insiste-se na questão da identidade em decorrência de suas íntimas implicações com a arte liberal de governar emergente no Ocidente. Nunca se preocupou tanto em identificar - e o problema do anonimato torna-se central no deslocamento do modo disciplinar de sociedade para as sociedades de controle, conforme descritas por Gilles Deleuze (2008).

No "delito" cometido por Indianara, a questão da identificação é fundamental, já que o delito só existe se a verdade do delinquente confirmá-lo: afinal, esta pessoa que está mostrando os seios no meio da rua é homem ou mulher? Quando Indianara prejudica a identificação, embaralhando signos corporais e jurídicos performativos do gênero, colocase uma situação paradoxal e a aplicação da lei penal fica em suspenso, diante do perigo de criar precedentes ameaçadores ao status quo.

A partir da discussão ora empreendida, podemos perguntar se e como um corpo que não está modelado no padrão cissexista de gênero é capturado por novas estratégias governamentais, bem como indagar a respeito da natureza de tais estratégias. $O$ tratamento desta questão se dará por duas vias - uma que diz respeito à localização dos sujeitos desviantes em um campo de visibilidade abjeta, nas "bordas do humano" (NARDI, 2014); a outra via tratará dos dispositivos específicos que emergem para dar conta ou reenquadrar as "desordens" de gênero, que nada mais são que desdobramentos do dispositivo de sexualidade que se afirma no século XIX.

No que tange ao campo da abjeção, em oposição ao campo dos sujeitos legitimados socialmente pelos mecanismos de normalização, é importante retomar o contexto histórico contemporâneo do Brasil para explicitar a lógica higienista e eugenista que o autoritarismo encarnado nas oligarquias, no populismo e nas ditaduras utiliza para produzir dinâmicas sociais que colocam indivíduos na borda do humano (NARDI, 2014) este humano culturalmente constituído a partir de uma concepção colonialista, ou seja: branco, heterossexual, cristão, burguês e primeiro-mundista. Os indivíduos à margem deste ideal são deslocados para fora do campo da biolegitimidade, o que significa que suas vidas não são dignas de investimento estatal no que tange à proteção - não são estas que o Estado busca "fazer viver". Tal movimento excludente não se resume à ação estatal, estando permeado na dinâmica social, conforme já exemplificado no decorrer deste artigo. Afinal, conforme apontado por Rabinow e Rose (2006), "o biopoder contemporâneo é uma forma de poder que em última instância repousa sobre o poder de alguns de ameaçar a morte de outros" (p. 30).

A abjeção não implica invisibilidade, mas, ao contrário, uma demarcação constante de territórios a partir de insultos, da violência e do gozo dali derivado. O investimento estatal é justamente no sentido de manter as fronteiras bem delimitadas e adequadamente permeáveis, para se permitir o gozo cotidiano dos sujeitos no exercício da violência, a fim de manter a limpeza da nação e a defesa da moral e dos bons costumes, além, é claro, de nutrir o jogo de repulsa e sedução pela abjeção, delimitando materialmente os territórios em que o gozo a partir da abjeção poderá ocorrer (NARDI, 2014). Tal funcionamento se explicita no momento da prisão de Indianara. Como ela própria relata, ${ }^{4}$ os policiais pensaram que seria apenas mais uma travesti detida, em quem poderiam bater e depois "mandar embora". Quando se notou, porém, as articulações desta "travesti" com lideranças do movimento da Marcha das Vadias, profissionais respeitadas e que, portanto, não habitam o território da abjeção, a abordagem policial mudou e abrandou-se.

${ }^{4}$ Ver nota de rodapé número 2. 
Além disso, habitar as margens não significa que esses corpos estejam menos ligados, como aponta Foucault (2006), de maneiras numerosas e sutis com a economia, com a produção e o consumo. Conforme demonstrado no estudo etnográfico de Marcos Benedetti (2005), que acompanhou travestis em um ponto de prostituição de Porto Alegre, há todo um mercado aberto e explorado pela lacuna deixada pelos meios formais: costureiros e sapateiros especializados em roupas que se ajustam aos corpos das travestis, que vendem suas mercadorias nos próprios pontos de prostituição; ou, ainda, a figura das bombadeiras, responsáveis pelas intervenções nos corpos das travestis, realizando-a partir de implantes de silicone e outras técnicas - toda uma modelagem em seus corpos. Intervenções corporais desejadas por muitas mulheres cisgêneras e que médicos realizam em escala industrial nos hospitais das metrópoles, porém cujo acesso é barrado às travestis.

Não podemos desconsiderar que houve avanços na obtenção de direitos e na proteção estatal. Porém, há um movimento conservador e de resistência correlato, que justamente se nutre da racionalidade neoliberal de governar que afirma "o sujeito empreendedor de si mesmo e a manutenção de hierarquias sociais sustentadas nas relações autoritárias de gênero e no combate à laicidade do Estado" (NARDI, 2014, p. 220).

Podemos relacionar esses movimentos de resistência conservadora às mudanças contemporâneas ocorridas no dispositivo de sexualidade (FOUCAULT, 2006), cujos catalisadores foram o feminismo, o movimento de contracultura, dos direitos humanos e sexuais, e, mais especificamente, no Brasil, o processo de redemocratização, a constituição de 1988, as reformas e inovações no sistema de saúde e os novos movimentos sociais (NARDI, 2014).

Os embates entre o conservadorismo e os movimentos para diversidade sexual e de gênero estão imbricados com as transformações acima descritas. Entretanto, as políticas LGBT no Brasil têm adquirido um caráter eminentemente identitário, o que representa um risco de normalização e afirmação de hierarquias (NARDI, 2014). Percebe-se, portanto, a confluência entre essa afirmação identitária e o próprio funcionamento da lógica governamental neoliberal, que se sustenta em identidades. Entendemos, portanto, que as transformações no dispositivo de sexualidade são também manobras biopolíticas que podem dotar de maior eficácia a condução das condutas, o governo dos homens, das mulheres, dos gays, das lésbicas, das pessoas trans, sem deixar de lado o quinhão de liberdade necessário ao entendimento de sociedade como composto por empresas individuais.

Percebe-se uma tentativa correlata com o surgimento da transexualidade enquanto desdobramento do dispositivo de sexualidade, possibilitado pela própria invenção da figura identitária da/o "transexual" (BENTO, 2006). Tal desdobramento do dispositivo de sexualidade mostra-se como mais uma estratégia biopolítica de tentativa de captura dos corpos que subvertem o imperativo cissexual.

Constrói-se, dessa forma, uma terapêutica e uma parafernália tecno-burocrática para tratar os "disfóricos" de gênero, partindo de uma concepção de sujeito disfórico de gênero específica, constituída especialmente pelo saber médico. É justamente esta parafernália e os estereótipos decorrentes do saber constituído a respeito das/os trangêneros - como, por exemplo, de que elas/es teriam necessariamente repulsa por seus órgãos genitais, de que elas são mulheres presas em corpos de homens e vice-versa e que todas/ os desejam a cirurgia de transgenitalização - as especificidades da experiência transexual contemporânea e que a diferencia de outros fatos culturais de trânsito entre gêneros (BENTO, 2006).

Neste desdobramento do dispositivo da sexualidade em que se constitui a transexualidade, busca-se também atingir a verdade última do sujeito. Nesse caso, o objetivo 
é descobrir quem é o/a transexual verdadeiro/a que faz jus ao diagnóstico e, consequentemente, à cirurgia de transgenitalização. A partir desta demanda é que se alicerça o extenso protocolo pelo qual a/o candidata/o à cirurgia deve passar. Paradoxalmente, o que se objetiva é o apagamento semicompleto do percurso. A ideia de passabilidade como proteção contra a discriminação e violência é um aspecto paradoxal que se aproxima da norma ao buscar os privilégios da fantasia que vivemos em relação ao que seria uma mulher ou um homem "de verdade". O que significa, de acordo com a matriz de inteligibilidade de gênero, possuir um desejo heterossexual e, quiçá, constituir uma relação afetivo-amorosa com um parceiro do sexo oposto.

Bento (2006) descreve minuciosamente a construção do sujeito transexual no ambiente hospitalar, asseverando que as observações de médicos/as, enfermeiros/as, psicólogos/as, nesse contexto, não são apenas descritivas ou prescritivas, mas também performativas:

No dispositivo da transexualidade, nada é enunciação constatativa. Mais do que uma fábrica de corpos dimórficos, o hospital tenta reorganizar as subjetividades apropriadas para "um homem/uma mulher de verdade". No hospital, realiza-se um trabalho de "assepsia de gênero", retirando tudo que sugira ambigüidades e possa pôr em xeque um dos pilares fundantes das normas de gênero: o dimorfismo natural dos gêneros (BENTO, 2006, p. 67-68).

Busca-se encontrar algo escondido no íntimo da pessoa transexual, em consonância com a noção de que o sexo do indivíduo é algo que lhe escapa incessantemente, necessitando de alguém dotado de um saber científico para extrair a sua verdade última. Isso é evidenciado no protocolo do processo transexualizador, que exige pelo menos dois anos de acompanhamento, sendo o objetivo último do protocolo que a concorrente à cirurgia prove ser uma transexual verdadeira (BENTO, 2006; CONSELHO FEDERAL DE MEDICINA, 2010; BRASIL, 2013). Novamente, visualizamos com toda a força a ideia de uma essência verdadeira, uma essência (trans)gênera, que pode realizar a cirurgia de transgenitalização e se tornar, como se diz no senso comum, senão um/uma "mulher/homem de verdade", um/uma "operada/o".

Porém, como já afirmamos, Bento (2006) sugere que, na verdade, todas/os somos operadas/os, os corpos já nascem operados e são investidos durante toda a vida por tecnologias sociais precisas. A partir do pensamento de Beatriz Preciado, a autora descreve o caráter protético dos corpos, ou seja, como constituídos de próteses e tecnologias sofisticadas, não existindo um corpo in natura, sem que um discurso lhe atribua sentido. Conforme a transexualidade exemplifica, enquanto desdobramento do dispositivo de sexualidade, o biopoder exerce sua normalização sobre os corpos de maneira cada vez mais sofisticada.

Retornamos, aqui, ao corpo de Indianara e sua situação paradoxal. Conforme Foucault (2006), onde há poder, há resistência, e esta não é de forma alguma exterior às relações de poder/saber. Indianara apropria-se dessas intervenções corporais e denuncia o fato de algumas cirurgias, algumas próteses, serem mais bem aceitas do que outras. Ou melhor, algumas próteses são mais bem aceitas em determinados corpos do que em outros. Afinal, todos e todas que transitam e se deslocam entre as categorias binárias sexo e gênero, cultura e natureza, masculino e feminino, evidenciam o caráter produzido dos corpos através da produção tecnológica, constituída por "fluxos de silicone, hormônios, técnicas cirúrgicas" (Pedro Paulo Gomes PEREIRA, 2008) além de "fluxo de representações" (Idem). Estas tecnologias de normalização podem ser apropriadas de maneira subversiva, criando corpos não inteligíveis a partir da matriz heterocissexual binária. Há, portanto, a afirmação da assertiva de que os corpos não são somente passivamente constituídos 
mediante os mecanismos do biopoder, mas se reinventam e se produzem ativamente dentro das redes de poder:

O corpo está longe de ser o efeito de um sistema fechado de poder ou de ideias que atuam na matéria passiva; ao contrário, pode-se defini-lo como o nome de um dispositivo sexo-político - a medicina, a pornografia, os vibradores -; dispositivo este que é reapropriado pelas minorias sexuais, pelos seres "abjetos" e "anormais". O corpo não é um dado passivo de um biopoder, mas a potência que torna possível a incorporação prostética dos gêneros; a sexopolítica não é apenas um lugar do poder, mas o espaço de uma criação onde se sucedem e se justapõem homossexuais, movimentos feministas, transexuais, inter-sexuais, transgêneros. Esses corpos desestabilizam a heterossexualidade e a própria economia do poder (PEREIRA, 2008, p. 506).

Entendemos aqui como o jogo de máscaras, paródias de gênero, performances, constituem-se como verdadeiros problemas de gênero, criando confusão dentro do próprio sistema de governamentalidade neoliberal que diz que devemos operar nossos corpos, a fim de aumentar nosso capital humano, num processo de normalização infinito, porém respeitados certos limites discursivos de sexo-gênero.

A apropriação e a exibição que Indianara e tantos outros que transitam entre as fronteiras de gênero fazem dessas tecnologias corporais é uma forma de questionar o preço, não no sentido mercadológico, mas no sentido ético-estético-político dessa forma de ser governado.

Há a afirmação, portanto, de uma possibilidade de desgoverno dentro do próprio campo da governamentalidade. Os dispositivos acima delineados (aliança, sexualidade, transexualidade) não dão conta do ato performativo de Indianara e seu corpo que desconcerta e surpreende. Por fim, uma ação performativa que funciona como uma contraconduta ou, ainda, uma apropriação subversiva deste dispositivo sexo-político que tanto nos fascina e nos governa desde o século passado.

\section{Considerações finais}

No decorrer do presente artigo, buscou-se analisar as articulações e apoios mútuos entre, de um lado, a arte liberal de governar e sua correlata biopolítica e, de outro, as noções de sexo, gênero e de sexualidade. Para realizar tal intento, o "problema de gênero" causado por Indianara serviu de analisador dessas articulações, catalisando os elementos teóricos que foram sendo apresentados ao longo da explanação, a saber: a íntima relação entre o surgimento de razões governamentais específicas no Ocidente e o nascimento da biopolítica, com seu dispositivo de sexualidade. Pensou-se, por fim, nos desdobramentos do dispositivo de sexualidade a partir das últimas décadas do século passado até os dias atuais, quando a emergência de novos saberes e tecnologias passa a atuar no sentido de capturar os corpos, como o de Indianara e tantos outros/outras, que não se conformam aos imperativos heterossexual e cissexual. Porém, ao mesmo tempo, apontamos para o aspecto inexorável da governamentalidade, pois, dentro do seu próprio bojo, emerge também a crítica e a resistência. Resistência que transparece no ato performativo de gênero de Indianara que confunde e subverte os limites discursivos estabelecidos para o sexo e o gênero, habitando as fronteiras e assumindo sua ambiguidade, colocando um paradoxo a quem tenta decidir o que o sujeito é.

O ato performativo que deu início ao ensaio realiza, portanto, um embaralhamento que não se restringe à questão do corpo-sexo-gênero, mas diz respeito ao próprio entendimento da constituição do sujeito, de sua materialidade, de sua ontologia. Entendimentos que constituem o arcabouço epistemológico para determinadas formas de 
governar os sujeitos. É um ato, portanto, que rompe com a matriz de inteligibilidade cultural e denuncia os limites discursivos da cultura no que diz respeito ao sexo e ao gênero. É um ato que, muito mais do que comunicar algo, silencia. É a potência da não comunicação, conforme Deleuze (2008):

\begin{abstract}
Você pergunta se as sociedades de controle ou de comunicação não suscitarão formas de resistência capazes de dar novas oportunidades a um comunismo concebido como "organização transversal de indivíduos livres". Não sei, talvez. Mas isso não dependeria de as minorias retomarem a palavra. Talvez a fala, a comunicação estejam apodrecidas. Estão inteiramente penetradas pelo dinheiro: não por acidente, mas por natureza. É preciso um desvio da fala. Criar foi sempre coisa distinta de comunicar. O importante talvez venha a ser criar vacúolos de não-comunicação, interruptores, para escapar ao controle (p. 217).
\end{abstract}

\title{
Referências
}

BENEDETTI, Marcos. Toda feita: o corpo e o gênero das travestis. Rio de Janeiro: Garamond, 2005.

BENTO, Berenice. A reinvenção do corpo: sexualidade e gênero na experiência transexual. Rio de Janeiro: Garamond, 2006.

BRASIL. Decreto-Lei $n .^{\circ} 2.848$, de 7 de dezembro de 1940. Código Penal. Disponível em: http://www.planalto.gov.br/ccivil_03/decreto-lei/del2848.htm.

BRASIL. Lei . $^{\circ}$ 6.015, de 31 de dezembro de 1973. Dispõe sobre os registros públicos, e dá outras providências. Disponível em: http://www.planalto.gov.br/ccivil_03/leis/ 16015compilada.htm.

BRASIL. Lei $n .^{\circ}$ 10.406, de 10 de janeiro de 2002. Institui o Código Civil. Disponível em: http:/ /www.planalto.gov.br/ccivil_03/leis/2002/110406.htm.

BRASIL, Ministério da Saúde. Pötaria n. ${ }^{\circ}$ 2.803, de 19 de novembro de 2013. Redefine e amplia o Processo Transexualizador no Sistema Único de Saúde (SUS). Disponível em: http://bvsms.saude.gov.br/bvs/saudelegis/gm/2013/prt2803_19_11_2013.html.

BUTLER, Judith. Problemas de gênero: feminismo e subversão dāidentidada. Rio de Janeiro: Civilização Brasileira, 2003.

CONSELHO FEDERAL DE MEDICINA. Resolução n. 1955/2010. Dispõe sobre a cirurgia de transgenitalismo e revoga a Resolução CFM n. ${ }^{\circ}$ 1.652/02. Disponível em: http:// www.portalmedico.org.br/resolucoes/CFM/2010/1955_2010.htm.

DELEUZE, Gilles. Conversações. São Paulo: Editora 34, 2008.

FOUCAULT, Michel. "O que é a Crítica. Qu'est-ce que la critique? Critique et Aufklärung". Bulletin de la Société française de philosophie, v. 82, n. 2, p. 35-63, avr/juin 1990. Tradução de Gabriela Lafetá Borges e revisão de Wanderson Flor do Nascimento. . Vigiar e punir: nascimento da prisão. Petrópolis: Vozes, 1999. . História da sexualidade: a vontade de saber. v. I. São Paulo: Graal, 2006.

. Nascimento da biopolítica. Curso dado no Collège de France (1978-1979). São Paulo: Martins Fontes, 2008.

GUARANHA, Camila; LOMANDO, Eduardo. "Senhora, essa identidade não é sua!: reflexões sobre a transnomeação". In: NARDI, Henrique Caetano; SILVEIRA, Raquel da Silva; MACHADO, Paula Sandrine (Orgs.). Diversidade sexual, relações de gênero e políticas públicas. Porto Alegre: Sulina, 2013.

ICONOCLASTIA INCENDIÁRIA. Indianara Siqueira: a Trans que pode mudar a lei brasileira, 2013. Disponível em: http://iconoclastia.org/2013/06/10/indianara-siqueira-a-trans-quepode-mudar-a-lei-brasileira/. 
LOURAU, René. "Análise institucional e práticas de pesquisa". In: René Lourau na UERJ. Rio de Janeiro: UERJ, 1993.

"Uma apresentação da análise institucional". In: ALTOÉ, Sônia (Org.). René Lourau: analista institucional em tempo integral. São Paulo: Hucitec, 2004.

LOURO, Guacira Lopes. Um corpo estranho: ensaios sobre sexualidade e teoria queer. Belo Horizonte: Autêntica, 2004.

MÉLLO, Ricardo Pimentel; PAOLO, Ângela Flexa. "Subjetivações, identidades e o linguajar". Estudos e Pesquisas em Psicologia, UERJ, v. 7, n. 3, p. 490-501, dez. 2007.

NARDI, Henrique Caetano. "Nas bordas do humano: lutas pelo reconhecimento e capturas identitárias". In: RODRIGUES, Alexsandro; DALLAPICULA, Catarina; FERREIRA, Sérgio R. da S. (Orgs.). Transposições: Iugares e fronteiras em sexualidade e educação. Vitória: EDUFES, 2014. p. 213-225.

PEREIRA, Pedro Paulo Gomes. "Corpo, sexo e subversão: reflexões sobre duas teóricas queer". Interface - Comunicação, Saúde, Educação, v. 12, n. 26, p. 499-512, jul./set. 2008.

RABINOW, Paul; ROSE, Nikolas. "O conceito de biopoder hoje". Política e Trabalho, n. 24, p. 27-57, abr. 2006.

SCOT, Joan. "Gênero: uma categoria útil de análise histórica". Educação e realidade, Porto Alegre, n. 16, v. 2, jul./dez. 1990.

TONELI, Maria Juracy Filgueiras; AMARAL, Marília dos Santos. "Sobre travestilidades e políticas públicas: como se produzem os sujeitos da vulnerabilidade". In: NARDI, Henrique Caetano; SILVEIRA, Raquel da Silva; MACHADO, Paula Sandrine (Orgs.). Diversidade sexual, relações de gênero e políticas públicas. Porto Alegre: Sulina, 2013.

[Recebido em 28/10/2015,

reapresentado em $06 / 10 / 2016$

e aprovado em 13/02/2017]

An (Un)Governed Body: Gender, Hierarchy, Governamentality and Biopolitics

Abstract: This paper analyzes the articulations among neoliberal governmentality, biopolitics and the notions of sex, gender and sexuality. Furthermore, it aims at demonstrating how the destabilization of the binary gender identity logic threatens certain forms of governing and, also, how the norm can be rearranged producing strategies to embody bodies produced in the contrary of the cissexist pattern. In order to achieve that, the "gender trouble" caused by Indianara, who identifies as a trans person and who was arrested during a Slut Walk while walking bare breast, served as an analyzer of such articulations, through the chosen conceptual composition. Keywords: Gender; Sex; Sexuality; Biopolitcs; Governmentality

Felipe Luckmann (elipelu86@gmail.com) é graduado em psicologia pela Pontifícia Universidade Católica do Rio Grande do Sul, e especialista em Análise Institucional pela Universidade Federal do Rio Grande do Sul. Estuda gênero e sexualidade a partir da obra de Michel Foucault e dos teóricos queer. Atua também na área de gestão de pessoas da Justiça do Trabalho/RS.

Henrique Caetano Nardi (hcnardi@gmail.com) possui graduação em Medicina pela Universidade Federal do Rio Grande do Sul e residência em Medicina Social. É mestre e doutor em Sociologia pela Universidade Federal do Rio Grande do Sul. Atualmente é Professor Associado da Universidade Federal do Rio Grande do Sul e Diretor do Instituto de Psicologia. É coordenador do Núcleo de Pesquisa em Sexualidade e Relações de Gênero (NUPSEX) e do Centro de Referência em Direitos Humanos: Relações de Gênero, Diversidade Sexual e Raça (CRDH) do Instituto de Psicologia da UFRGS. 